\title{
Factors contributing to lack of interest in research among medical students
}

This article was published in the following Dove Press journal:

Advances in Medical Education and Practice

6 November 2013

Number of times this article has been viewed

\author{
Ali Sibtain Farooq Sheikh ${ }^{1,2}$ \\ Saman Ali Sheikh ${ }^{3}$ \\ Ahmad Kaleem ${ }^{1,2}$ \\ Ahmad Waqas' \\ 'King Edward Medical University, \\ Lahore, ${ }^{2}$ Mayo Hospital, Lahore, \\ ${ }^{3}$ Ziauddin University, Karachi, Pakistan
}

Background: Research experiences early in the medical student's education are an important factor for attracting a greater number of doctors to careers with a research component.

Objective: To determine the factors contributing to a lack of enthusiasm about research activities among medical students, and to suggest ways to help students develop an interest in research.

Design: A medical institution-based, case-control study was conducted. A case was defined as any fourth year medical student who believed that undertaking research was not interesting; controls were matched for age and sex. A pretested, structured, and self-administered questionnaire was used; the data were analyzed using statistical methods.

Results: In all, 122 students ( $54 \%$ male, $46 \%$ female) were recruited to the study. Factors found to be significant were lack of Internet facilities (odds ratio 0.218 ) and considering research useless (odds ratio 4.570).

Conclusion: Measures should be taken at undergraduate level to involve students in research activities. Ensuring easy access to Internet facilities could be one positive step. Further research should be done to explore the reasons why some medical students consider research useless.

Keywords: research, lack of interest, medical students, physician-scientists

\section{Introduction}

Research is a human activity based on the use of intellect to investigate, interpret, and revise human knowledge about different aspects of the world. Research updates medical students on the latest advances in medicine and science and provides new interpretations of existing facts. However, a trend away from research activities has been seen, particularly in developing countries. ${ }^{1-10}$ In Pakistan, a decreased level of interest in research is seen in some medical students, ${ }^{7}$ resulting from a variety of factors needing to be identified and approached. ${ }^{11}$

In research conducted at Aga Khan University (Karachi, Pakistan), it was found that knowledge of research is lower, and attitudes more indifferent, during the initial years of medical school. ${ }^{7}$ Another study showed that students face a number of problems in conducting research: curriculum overload, time limitation, lack of proper training, uncooperative staff, and lack of motivation and incentives. ${ }^{8}$ Another study at the same university established that students undergoing lecture-based learning showed less interest in health research than those undergoing problem-based learning. ${ }^{12}$ It has been found that lack of interest in research among medical students results from insufficient attention given by the faculty and administration to medical students, which can be improved by a well-considered approach. ${ }^{13}$ Another study showed that lack of interest
Correspondence: Ali Sibtain Farooq Sheikh

King Edward Medical University, Nila

Gumbad,Anarkali, Lahore 54000, Pakistan

Tel +923004438237

Email asfsheikh@gmail.com 
in research is more prevalent among medical students studying in public medical schools than among those in private medical schools. ${ }^{14}$

Physician-scientists are key players in the research community. They can treat patients in amazingly effective ways. ${ }^{9,10,13}$ Increasingly, medical research has emphasized the need for recruiting more and more physicians to research careers. Increasing physician contributions leads to an increase in the number of studies, an increase in public education, and an increase in subject recruitments for various trials. ${ }^{15} \mathrm{~A}$ decreasing trend in the number of doctors pursuing a research career has been seen in the United States. To counterbalance this situation, a number of solutions have been put into effect. However, most of these focus on postdoctoral fellowships and other higher-level programs, with almost no attention paid to the medical student's early research opportunities. ${ }^{16,17}$ Increased participation of medical students in research activities could have a positive influence on their career choice. ${ }^{9,18-24}$ For instance, medical students with good research skills could have increased employment options in their future career. ${ }^{25-28}$ Between 1987 and 1997, there was a significant decrease in graduation numbers of premedical and medical students who had a strong research interest. These students included both sexes; men showed a greater desire for research careers, but did not achieve graduation rates as frequently as women. Furthermore, women who had strong research interests after matriculation had a decreased interest during medical school. ${ }^{29}$

Lack of interest in research activities, by depriving medical students of the understanding and utilization of latest medical advances, has led to deterioration in the health care system. ${ }^{30}$ As very few studies have been conducted on the lack of interest in research activities, including in Lahore, Pakistan, we structured our study to explore the extent and distribution of the problem in different socio-economic groups. We investigated the various social factors responsible for the problem of decreased interest in research and suggested means to solve it, so that the authorities concerned might be able to redesign policies for the benefit of communities.

\section{Methods}

\section{Study design}

The study was performed from July 2007 to December 2007. Approval was received from the ethics committee of King Edward Medical University, Pakistan. It was an institution-based case-control study with subjects matched for age and sex, to investigate the factors contributing to the lack of interest in research among medical students during the fourth year of a Bachelor of Medicine (MB) or
Bachelor of Surgery (BS) at King Edward Medical University, Pakistan.

King Edward University is a public medical institution located near Nila Gumbad in Lahore; its style of teaching is primarily lecture-based. According to 2013 statistics, it is ranked by the higher education commission among the best medical universities in Pakistan. ${ }^{31,32}$ The initial two years of medical school focus on basic science, whereas the later years involve greater exposure to clinical departments and research options.

Research activity is a mandatory component of the fourth year class; at the time of this study, 175 students were enrolled in the class and were included in our study population. A sample size of 122 students met the objectives of this study at $95 \%$ confidence interval (CI). The sample size was calculated using Raosoft (available online from www.raosoft.com), assuming a $50 \%$ response distribution and a $5 \%$ margin of error. The students were randomly chosen to participate in the study's simple random sampling.

\section{Case-control definitions}

A case was defined as any fourth year medical student younger than 30 years of age who believed that undertaking research is not interesting. A control was defined as any fourth year medical student younger than 30 years of age who believed that undertaking research is interesting; each control was matched to a case for sex and age in years. All other students of the University, teaching staff, and official staff were excluded from the study.

\section{Data collection and analysis}

An interview schedule was designed to collect information using a pretested, structured, and self-administered questionnaire to gather data. Extensive discussions with the faculty of the Community Medicine department were undertaken before approving the questionnaire for use. The questionnaire was then tested on a small group of students from the same class to identify the factors most relevant to the topic of lack of interest in research among medical students. Further discussions with faculty members helped us formulate the final questionnaire.

Written informed consent was provided by all participants. Demographic details collected from the participants included age, sex, and hometown. Factors considered relevant according to the questionnaire design were presented in a yes/no format to participants. The responses are shown in Table 1.

The data collection process was closely supervised by the staff of the Community Medicine department, who reviewed the completed data collection questionnaires. Data 
Table I Responses of medical students concerning possible factors that are responsible for causing a lack of interest in research

\begin{tabular}{|c|c|c|c|c|c|c|c|c|}
\hline \multirow[t]{2}{*}{ Variable } & \multicolumn{2}{|c|}{ Case } & \multicolumn{2}{|c|}{ Control } & \multirow[t]{2}{*}{ Crude OR } & \multirow[t]{2}{*}{$95 \% \mathrm{Cl}$} & \multirow[t]{2}{*}{ OR } & \multirow[t]{2}{*}{$95 \% \mathrm{Cl}$} \\
\hline & $\mathbf{n}$ & $\%$ & $\mathbf{n}$ & $\%$ & & & & \\
\hline \multicolumn{9}{|l|}{ I. Sex } \\
\hline Male & 33 & 50.0 & 33 & 50.0 & 1.000 & $0.49 I-2.038$ & 0.735 & $0.259-2.083$ \\
\hline Female & 28 & 50.0 & 28 & 50.0 & 1.000 & & 1.000 & \\
\hline \multicolumn{9}{|c|}{ 2. Curriculum overload } \\
\hline Yes & 49 & 47.1 & 55 & 52.9 & 0.445 & $0.155-1.277$ & 0.396 & $0.100-1.564$ \\
\hline No & 12 & 66.7 & 6 & 33.3 & 1.000 & & 1.000 & \\
\hline \multicolumn{9}{|c|}{ 3. Sleep loss } \\
\hline Yes & 27 & 61.4 & 17 & 38.6 & 2.055 & $0.967-4.369$ & 1.463 & $0.462-4.625$ \\
\hline No & 34 & 43.6 & 44 & 56.4 & 1.000 & & 1.000 & \\
\hline \multicolumn{9}{|l|}{ 4. Fatigue } \\
\hline Yes & 43 & 60.6 & 28 & 39.4 & 2.815 & $1.335-5.936$ & 2.640 & $0.923-7.547$ \\
\hline No & 18 & 35.3 & 33 & 64.7 & 1.000 & & 1.000 & \\
\hline \multicolumn{9}{|c|}{ 5. Extracurricular activities } \\
\hline Yes & 29 & 58.0 & 21 & 42.0 & 1.726 & $0.833-3.578$ & 1.569 & $0.563-4.374$ \\
\hline No & 32 & 44.4 & 40 & 55.6 & 1.000 & & 1.000 & \\
\hline \multicolumn{9}{|c|}{ 6. You find research useless } \\
\hline Yes & 35 & 72.9 & 13 & 27.1 & 4.970 & $2.243-11.014$ & 4.570 & $1.514-13.800$ \\
\hline No & 26 & 35.1 & 48 & 64.9 & 1.000 & & 1.000 & \\
\hline \multicolumn{9}{|c|}{ 7. Lack of previous exposure } \\
\hline Yes & 26 & 39.4 & 40 & 60.6 & 0.390 & $0.187-0.811$ & 0.445 & $0.165-1.202$ \\
\hline No & 35 & 62.5 & 21 & 37.5 & 1.000 & & 1.000 & \\
\hline \multicolumn{9}{|c|}{ 8. Internet inexperience } \\
\hline Yes & 14 & 37.8 & 23 & 62.2 & 0.492 & $0.223-1.084$ & 0.522 & $0.166-1.644$ \\
\hline No & 47 & 55.3 & 38 & 44.7 & 1.000 & & 1.000 & \\
\hline \multicolumn{9}{|c|}{ 9. Uncooperative colleagues } \\
\hline Yes & 37 & 51.4 & 35 & 48.6 & 1.145 & $0.556-2.358$ & 0.994 & $0.348-2.839$ \\
\hline No & 24 & 48.0 & 26 & 52.0 & 1.000 & & 1.000 & \\
\hline \multicolumn{9}{|c|}{ 10. Uncooperative community } \\
\hline Yes & 28 & 46.7 & 32 & 53.3 & 0.769 & $0.378-1.566$ & 0.522 & $0.182-1.502$ \\
\hline No & 33 & 53.2 & 29 & 46.8 & 1.000 & & 1.000 & \\
\hline II. Imprope & & & & & & & & \\
\hline Yes & 30 & 57.7 & 22 & 42.3 & 1.716 & $0.83 I-3.54 \mid$ & 0.610 & $0.208-1.789$ \\
\hline No & 31 & 44.3 & 39 & 55.7 & 1.000 & & 1.000 & \\
\hline 12. Lack of I & & & & & & & & \\
\hline Yes & 20 & 52.6 & 18 & 47.4 & 1.165 & $0.54 I-2.510$ & 1.404 & $0.473-4.165$ \\
\hline No & 41 & 48.8 & 43 & 51.2 & 1.000 & & 1.000 & \\
\hline 13. Finding a & & & & & & & & \\
\hline Yes & 28 & 44.4 & 35 & 55.6 & 0.630 & $0.308-1.288$ & 0.579 & $0.212-1.582$ \\
\hline No & 33 & 55.9 & 26 & 44.1 & 1.000 & & 1.000 & \\
\hline 14. Selecting & & & & & & & & \\
\hline Yes & 32 & 48.5 & 34 & 51.5 & 0.876 & $0.430-1.787$ & 1.063 & $0.367-3.080$ \\
\hline No & 29 & 51.8 & 27 & 48.2 & 1.000 & & 1.000 & \\
\hline 15. Bad past & ence & mple, & & & & & & \\
\hline Yes & 17 & 54.8 & 14 & 45.2 & 1.297 & $0.572-2.940$ & $2.24 I$ & $0.627-8.004$ \\
\hline No & 44 & 48.4 & 47 & 51.6 & 1.000 & & 1.000 & \\
\hline 16. Social co & ents & & & & & & & \\
\hline Yes & 29 & 56.9 & 22 & 43.1 & 1.607 & $0.778-3.317$ & 1.789 & $0.633-5.059$ \\
\hline No & 32 & 45.1 & 39 & 54.9 & 1.000 & & 1.000 & \\
\hline 17. Drugs/ac & & & & & & & & \\
\hline Yes & 15 & 65.2 & 8 & 34.8 & 2.160 & $0.840-5.556$ & 1.243 & $0.291-5.303$ \\
\hline No & 46 & 46.5 & 53 & 53.5 & 1.000 & & 1.000 & \\
\hline 18. Laziness & & & & & & & & \\
\hline Yes & 31 & 53.4 & 27 & 46.6 & 1.301 & $0.638-2.653$ & 0.965 & $0.376-2.473$ \\
\hline No & 30 & 46.9 & 34 & 53.1 & 1.000 & & 1.000 & \\
\hline
\end{tabular}


Table I (Continued)

\begin{tabular}{|c|c|c|c|c|c|c|c|c|}
\hline \multirow[t]{2}{*}{ Variable } & \multicolumn{2}{|c|}{ Case } & \multicolumn{2}{|c|}{ Control } & \multirow[t]{2}{*}{ Crude OR } & \multirow[t]{2}{*}{$95 \% \mathrm{Cl}$} & \multirow[t]{2}{*}{ OR } & \multirow[t]{2}{*}{$95 \% \mathrm{Cl}$} \\
\hline & $\mathbf{n}$ & $\%$ & $\mathbf{n}$ & $\%$ & & & & \\
\hline \multicolumn{9}{|c|}{ 19. Lack of Internet facilities } \\
\hline Yes & 23 & 41.1 & 33 & 58.9 & 0.514 & $0.249-1.057$ & 0.218 & $0.074-0.644$ \\
\hline No & 38 & 57.6 & 28 & 42.4 & 1.000 & & 1.000 & \\
\hline \multicolumn{9}{|c|}{ 20. Uncooperative faculty } \\
\hline Yes & 27 & 54.0 & 23 & 46.0 & 1.312 & $0.636-2.705$ & 0.751 & $0.219-2.57 \mid$ \\
\hline No & 34 & 47.2 & 38 & 52.8 & 1.000 & & 1.000 & \\
\hline \multicolumn{9}{|c|}{ 2I. Transportation problems } \\
\hline Yes & 36 & 51.4 & 34 & 48.6 & $\mathrm{I} .144$ & $0.558-2.345$ & 1.854 & $0.623-5.519$ \\
\hline No & 25 & 48.1 & 27 & 51.9 & 1.000 & & 1.000 & \\
\hline \multicolumn{9}{|c|}{ 22. No motives and incentives } \\
\hline Yes & 38 & 55.1 & 31 & 44.9 & 1.599 & $0.777-3.289$ & 0.867 & $0.309-2.432$ \\
\hline No & 23 & 43.4 & 30 & 56.6 & 1.000 & & 1.000 & \\
\hline \multicolumn{9}{|c|}{ 23. Faculty-forced research } \\
\hline Yes & 45 & 55.6 & 36 & 44.4 & 1.953 & $0.909-4.199$ & 2.314 & $0.667-8.036$ \\
\hline No & 16 & 39.0 & 25 & 61.0 & 1.000 & & 1.000 & \\
\hline
\end{tabular}

Abbreviations: $\mathrm{n}$, number; $\mathrm{OR}$, odds ratio; $\mathrm{Cl}$, confidence interval.

were analyzed using Statistical Package for Social Sciences (SPSS, version 16.0.2; IBM Corporation, Armonk, NY, USA) software. Regression analysis was used to assess the relationship between different exposure, confounding, and outcome variables. In analyzing the results, a $P$-value of $<0.05$ was considered significant. Odds ratios (ORs) with a $95 \%$ confidence interval (CI) were calculated after applying bivariate analysis (crude OR) and multinomial logistic regression.

\section{Results}

In all, 122 students (61 cases, 61 matched-controls), all under 30 years of age, were recruited into the study; $54 \%$ were male and $46 \%$ were female.

Fewer of the cases than controls believed that curriculum overload, Internet inexperience, an uncooperative community, difficulty in finding a mentor, difficulty in selecting a topic, lack of previous exposure, and lack of Internet facilities lead to a lack of interest in research. There was no significant association between curriculum overload, Internet inexperience, an uncooperative community, difficulty in finding a mentor, difficulty in selecting a topic, lack of previous exposure, and lack of interest. After applying multinomial logistic regression, a lack of Internet facilities was found to be significantly associated with the lack of interest of medical students in research activities.

More cases than the controls believed that sleep loss, extracurricular activities, uncooperative colleagues, inclement weather (hot and humid), lack of knowledge, bad past experiences, social commitments, drugs/addictions, laziness, uncooperative faculty, transportation problems, lack of motives and incentives, faculty-forced research, fatigue, and an attitude that considered research useless led to a lack of interest in research. However, there was no significant association between sleep loss, extracurricular activities, uncooperative colleagues, improper weather, lack of knowledge, bad past experiences, social commitments, drugs/addictions, laziness, uncooperative faculty, transportation problems, lack of motives and incentives, faculty-forced research, fatigue, and lack of interest. Finding research useless was a significant factor associated with lack of interest of students in research activities. Students who consider research useless are 4.970 times more likely to be uninterested in research.

\section{Discussion}

After multinomial logistic regression, considering research useless and lack of Internet facilities emerged as the only significant factors in our study.

The Internet is a very important resource, and much past research would not have been as fruitful without it. Today the digital world embraces libraries that once used to be difficult to access across long distances. Medical databases such as PubMed, eMedicine, MEDLINE, and several others are particularly useful for finding research articles. These resources are important to research because they make recent information available; the Internet is very useful for other reasons as well. For example, Google, being a general search engine, has a large number of medical articles. Doctors have used these searches to diagnose many challenging cases. A Google or Google Scholar search is quite effective in helping doctors make a diagnosis. ${ }^{33-35}$ We strongly believe that much research is not feasible without access to the Internet. Better funding for research projects can have a significant impact on this. 
For example, provision of electronic media and Internet to students where these facilities are not available can counter this factor, as depicted by our research.

Burgoyne et $\mathrm{al}^{24}$ in their 2010 article supported our finding that students with no interest in research believe it to be useless; in this study, the students stated that researchers are cut off from clinical practice. This notion shows that students have a poor understanding of research and its vastness. Further research is needed in Pakistan to uncover any other reasons that might be responsible for this perception. The concept of translational research should be promoted among medical students.

Previous studies have shown an association between nonparticipation in research and an uncooperative faculty, a lack of motivation and incentives, ${ }^{8-10}$ curriculum overload, ${ }^{8,9}$ and lack of knowledge. ${ }^{9}$ We came to different conclusions through our research; however, these discrepancies are not truly contradictory. For example, Mokry and Mokra ${ }^{9}$ in a 2007 study found a relationship between students' participation in research and financial incentives. On the other hand, we did not define any particular benefits, such as finances. Furthermore, these studies count the above-mentioned factors as causing hindrance to student involvement, but most of the study subjects were interested in research activities, and the authors did not hold these factors responsible for causing a lack of interest. ${ }^{8-10}$ Hence, although these factors might be responsible for nonparticipation in research, we conclude that they are not responsible for causing a lack of interest. However, these factors cannot be ignored; improving these aspects of medical education can promote research activities. For example, the students' curriculum workload can cause time constraints, so small working groups can be formed to make the study process better. In addition, students can be encouraged to take part in stimulating activities like games or puzzles.

Medical student research programs have the proven benefit of increasing the number of research-oriented physicians. ${ }^{16,37,38}$ Their use is strongly recommended whenever feasible. ${ }^{16,36-38}$ Examples of these programs include the medical student research fellowship program (MSRF), ${ }^{16}$ the Doris Duke clinical research fellowship (CRF) program, ${ }^{39}$ the Norwegian medical student research program, ${ }^{38}$ the Baylor College of Medicine and Cleveland Clinic Learner $\mathrm{COM},{ }^{40}$ the student selected components (SSC) program in the UK, ${ }^{41}$ scholarly concentration (SC) programs at the Alpert medical school of Brown University, ${ }^{40}$ and mandatory medical students' research projects in the Netherlands. ${ }^{42}$ The Howard Hughes medical institute (HHMI) conducted two 1-year research training programs for concentrating on the awardees' research careers. A study conducted to evaluate the effect of those programs on medical students' decisions to take up a research career showed that these training programs had a lasting imprint on health professionals' careers. ${ }^{43}$ Undergraduate research electives can also help. A mandatory research elective during medical school makes a difference. A survey was conducted at the Queen's University (Kingston, ON, Canada) to determine students' views about such electives. It was unanimously agreed upon that a mandatory rotation has a positive impact, even if a research career is not eventually opted for. ${ }^{44}$

Seminars, symposiums and courses should be more frequently conducted to attract more students toward research activities. Such seminars may be focused on eliciting the importance of research, explaining different methods of research, and above all, showing the newer students the research work of experienced professionals. This can inspire medical students to do research, strengthen their careers, and be better doctors in the long run. In short, such activities have a positive impact on students. ${ }^{45,46}$

A review of the literature suggests a marked geographical variation in the level of participation by medical students in research projects. ${ }^{7,9,10,24,28,47,48}$ This variation is also prominent within a country and relies on factors such as the curriculum design and opportunities provided to potential researchers. ${ }^{10}$ Our findings are noteworthy in comparison to the existing literature. However, policymakers should use local data whenever possible for formulating policies favoring research among medical students.

To our knowledge, this study is the first to report most of the factor associations to interest in research. Although the progress in research and research-oriented careers could be hindered by Internet and computer inexperience, ${ }^{28}$ or the nonavailability of a mentor, ${ }^{47}$ they do not necessarily affect the level of interest of students in research activities.

\section{Conclusion}

Measures should be taken at undergraduate level to involve students in research activities. Ensuring easy access to Internet facilities is essential. Further studies should be conducted to find out the reasons why some medical students consider research useless, and steps should be taken to change these attitudes. Factors associated with decreased participation in research by those students who demonstrate a positive level of interest should also be explored.

There are a number of limitations to this study. First, it has been undertaken only in one university, in one class, 
and using a cross-sectional methodology. It is difficult to make generalized conclusions and causal relation-based recommendations. Second, this study has only collected binary answers. To analyze the complexity of social and academic issues that might influence the level of interest in research medicine, a stronger, more detailed study design would be valuable. Finally, the study was conducted on a senior class. The picture might be entirely different in junior classes as different levels of education are likely to motivate students in different ways.

\section{Acknowledgments}

The authors thank Professor Dr Maaz Ahmad and other members of the teaching staff of the Community Medicine department, King Edward Medical University, for their support, guidance, and supervision during the research process.

\section{Disclosure}

The authors report no conflicts of interest in this study.

\section{References}

1. Wyngaarden JB. The clinical investigator as an endangered species. N Engl J Med. 1979;301(23):1254-1259.

2. Goldstein JL, Brown MS. The clinical investigator: bewitched, bothered, and bewildered - but still beloved. J Clin Invest. 1997;99(12): 2803-2812.

3. Rosenberg LE. The physician-scientist: an essential - and fragile - link in the medical research chain. J Clin Invest. 1999;103(12):1621-1626.

4. Campbell EG, Weissman JS, Moy E, Blumenthal D. Status of clinical research in academic health centers: views from the research leadership. JAMA. 2001;286(7):800-806.

5. Mokry J, Sevecova D, Sulaj M. Student scientific activities at Jessenius Faculty of Medicine, Comenius University in Martin - current state and its future. Bratisl Lek Listy. 2004;105(1):25-29.

6. Ley TJ, Rosenberg LE. The physician-scientist career pipeline in 2005: build it, and they will come. JAMA. 2005;294(11):1343-1351.

7. Khan H, Khawaja MR, Waheed A, Rauf MA, Fatmi Z. Knowledge and attitudes about health research amongst a group of Pakistani medical students. BMC Med Educ. 2006;6:54.

8. Mostafa SR, Khashab SK, Fouaad AS, Abdel Baky MA, Waly AM. Engaging undergraduate medical students in health research: students' perceptions and attitudes, and evaluation of a training workshop on research methodology. J Egypt Public Health Assoc. 2006;81(1-2): 99-118.

9. Mokry J, Mokra D. Opinions of medical students on the pre-graduate scientific activities - how to improve the situation? Biomed Pap Med Fac Univ Palacky Olomouc Czech Repub. 2007;151(1):147-149.

10. de Oliveira NA, Luz MR, Saraiva RM, Alves LA. Student views of research training programmes in medical schools. Med Educ. 2011;45(7):748-755.

11. Salgueira A, Costa P, Gonçalves M, et al. Individual characteristics and student's engagement in scientific research: a cross-sectional study. BMC Med Educ. 2012;12:95.

12. Khan H, Taqui AM, Khawaja MR, Fatmi Z. Problem-based versus conventional curricula: influence on knowledge and attitudes of medical students towards health research. PLoS One. 2007;2(7): e632.

13. Zier K, Stagnaro-Green A. A multifaceted program to encourage medical students' research. Acad Med. 2001;76(7):743-747.
14. Kassebaum DG, Szenas PL, Ruffin AL, Masters DR. The research career interests of graduating medical students. Acad Med. 1995;70(9): 848-852.

15. Zier K, Friedman E, Smith L. Supportive programs increase medical students' research interest and productivity. J Investig Med. 2006; 54(4):201-207.

16. Solomon SS, Tom SC, Pichert J, Wasserman D, Powers AC. Impact of medical student research in the development of physician-scientists. J Investig Med. 2003;51(3):149-156.

17. Vujaklija A, Hren D, Sambunjak D, et al. Can teaching research methodology influence students' attitude toward science? Cohort study and nonrandomized trial in a single medical school. J Investig Med. 2010;58(2):282-286.

18. Fisher WR. Medical student research: a program of self-education. J Med Educ. 1981;56(11):904-908.

19. Campos-Outcalt D, Senf J, Watkins AJ, Bastacky S. The effects of medical school curricula, faculty role models, and biomedical research support on choice of generalist physician careers: a review and quality assessment of the literature. Acad Med. 1995;70(7):611-619.

20. Altunbas A, Cursiefen C. [Research activities of medical students in Germany using as an example the Würzburg University Clinic.] Dtsch Med Wochenschr. 1998;123(20):617-620. German [with English abstract].

21. Remes V, Helenius I, Sinisaari I. Research and medical students. Med Teach. 2000;22:164-167.

22. Lloyd T, Phillips BR, Aber RC. Factors that influence doctors' participation in clinical research. Med Educ. 2004;38(8):848-851.

23. Bierer SB, Chen HC. How to measure success: the impact of scholarly concentrations on students - a literature review. Acad Med. 2010;85(3): $438-452$.

24. Burgoyne LN, O'Flynn S, Boylan GB. Undergraduate medical research: the student perspective. Med Educ Online. 2010;15.

25. Leonard JC, Ellsbury KE. Gender and interest in academic careers among first- and third-year residents. Acad Med. 1996;71(5):502-504.

26. Jeste DV, Halpain MC, Trinidad GI, Reichstadt JL, Lebowitz, BD. UCSD's short-term research training programs for trainees at different levels of career development. Acad Psychiatry. 2007;31(2):160-167.

27. Lopatto D. Undergraduate research experiences support science career decisions and active learning. CBE Life Sci Educ. 2007;6(4): 297-306.

28. She L, Wu B, Xu L, Wu J, Zhang P, Li E. Determinants of career aspirations of medical students in southern China. BMC Med Educ. 2008;8:59.

29. Guelich JM, Singer BH, Castro MC, Rosenberg LE. A gender gap in the next generation of physician-scientists: medical student interest and participation in research. $J$ Investig Med. 2002;50(6):412-418.

30. Deressa W, Azazh A. Attitudes of undergraduate medical students of Addis Ababa University towards medical practice and migration, Ethiopia. BMC Med Educ. 2012;12:68.

31. HEC announced ranking of Pakistani universities 2013. The News International. July 05, 2013; Web Edition. Available from: http://www. thenews.com.pk/article-108140-HEC-announced-ranking-of-Pakistaniuniversities-2013. Accessed September 17, 2013.

32. Quality and research based ranking of Pakistani HEIs. Ranking, methodology, criteria and weights. Available from: http://www.hec.gov.pk/ InsideHEC/Divisions/QALI/Others/RankingofUniversities/Documents/ Quality\%20and\%20Research\%20Based \%20Ranking\%20of\%20Pakistan\%20HEIs_Updated.pdf. Accessed September 17, 2013.

33. Giustini D. How Google is changing medicine. BMJ. 2005;331(7531): $1487-1488$.

34. Henderson J. Google Scholar: A source for clinicians? CMAJ. 2005;172(12):1549-1550.

35. Tang H, Ng JH. Googling for a diagnosis - use of Google as a diagnostic aid: internet based study. BMJ. 2006;333(7579):1143-1145.

36. Jacobs CD, Cross PC. The value of medical student research: the experience at Stanford University School of Medicine. Med Educ. 1995;29(5):342-346. 
37. Frishman WH. Student research projects and theses: should they be a requirement for medical school graduation? Heart Dis. 2001;3(3): $140-144$.

38. Hunskaar S, Breivik J, Siebke M, Tømmerås K, Figenschau K, Hansen JB. Evaluation of the medical student research programme in Norwegian medical schools. A survey of students and supervisors. BMC Med Educ. 2009;9:43.

39. Gallin EK, Le Blancq SM; Clinical Research Fellowship Program Leaders. Launching a new fellowship for medical students: the first years of the Doris Duke Clinical Research Fellowship Program. J Investig Med. 2005;53(2):73-81.

40. Green EP, Borkan JM, Pross SH, et al. Encouraging scholarship: medical school programs to promote student inquiry beyond the traditional medical curriculum. Acad Med. 2010;85(3):409-418.

41. Robinson L, Drewery S, Ellershaw J, Smith J, Whittle S, MurdochEaton D. Research governance: impeding both research and teaching? A survey of impact on undergraduate research opportunities. Med Educ. 2007;41(8):729-736

42. van Eyk HJ, Hooiveld MH, Van Leeuwen TN, Van der Wurff BL, De Craen AJ, Dekker FW; NVMO-special Interest Group on Scientific Education. Scientific output of Dutch medical students. Med Teach. 2010;32(3):231-235
43. Fang D, Meyer RE. Effect of two Howard Hughes Medical Institute research training programs for medical students on the likelihood of pursuing research careers. Acad Med. 2003;78(12):1271-1280.

44. Houlden RL, Raja JB, Collier CP, Clark AF, Waugh JM. Medical students' perceptions of an undergraduate research elective. Med Teach. 2004;26(7):659-661.

45. Marusić A, Marusić M. Teaching students how to read and write science: a mandatory course on scientific research and communication in medicine. Acad Med. 2003;78(12):1235-1239.

46. Hren D, Lukić IK, Marusić A, et al. Teaching research methodology in medical schools: students' attitudes towards and knowledge about science. Med Educ. 2004;38(1):81-86.

47. Siemens DR, Punnen S, Wong J, Kanji N. A survey on the attitudes towards research in medical school. BMC Med Educ. 2010;10:4.

48. Vodopivec I, Vujaklija A, Hrabak M, et al. Knowledge about and attitudes towards science of first year medical students. Croat Med J. 2002;43:58-62.
Advances in Medical Education and Practice

\section{Publish your work in this journal}

Advances in Medical Education and Practice is an international, peerreviewed, open access journal that aims to present and publish research on Medical Education covering medical, dental, nursing and allied health care professional education. The journal covers undergraduate education, postgraduate training and continuing medical education

\section{Dovepress}

including emerging trends and innovative models linking education, research, and health care services. The manuscript management system is completely online and includes a very quick and fair peer-review system. Visit http://www.dovepress.com/testimonials.php to read real quotes from published authors.

Submit your manuscript here: http://www.dovepress.com/advances-in-medical-education-and-practice-journal 